\title{
Analysis of patients with septal abscess caused by electrocauterization of the nasal septum
}

\author{
Abdulvahap Akyigit ${ }^{1}$, Erol Keleș ${ }^{1}$, Turgut Karlıdağ ${ }^{1}$, \\ İrfan Kaygusuz', Mehmet Salih Yağmahan², Șinasi Yalçın \\ 1 Department of Otolaryngology, Firat University Faculty of Medicine, Elazığ, Türkiye \\ 2 Department of Otolaryngology, Doç. Dr. Yaşar Eryılmaz Doğubeyazıt State Hospital, Doğubeyazıt, Ağrı, Türkiye \\ Abdulvahap Akyigit, ORCID: 0000-0002-2192-155X \\ Erol Keleş, ORCID: 0000-0003-4443-6714 \\ Turgut Karlıdăg, ORCID: 0000-0003-2748-7309 \\ Irfan Kaygusuz, ORCID: 0000-0002-5237-2362 \\ Mehmet Salih Yağmahan, ORCID: 0000-0002-7150-6362 \\ Şinasi Yalçın, ORCID: 0000-0002-6528-9234
}

\begin{abstract}
Objective: Although nasal septal abscesses are mostly caused by trauma, they may occur due to non-traumatic causes. In the present study, we aimed to review patients who underwent electrocauterization of the nasal mucosa for epistaxis and subsequently developed a nasal septal abscess.
\end{abstract}

Methods: The study included 11 patients who underwent nasal electrocauterization for epistaxis and were subsequently admitted to our clinic with a pre-diagnosis of septal abscess for drainage of the abscess. The medical records of the patients, including details such as age, sex, duration of follow-up, symptoms, chronic diseases, microbiological cultures, radiological investigations and complications were retrospectively evaluated.

Results: Of the 11 patients included, seven were male and four were female with a mean age of $66.18 \pm 3.7$ years.
The mean duration of follow-up was $29.09 \pm 17.5$ months; five patients had both hypertension and diabetes mellitus, three patients had only diabetes mellitus and three patients had only hypertension. Microbiological culture of the purulent material collected during septal abscess drainage revealed no bacterial growth in six patients, growth of Staphylococcus aureus in two patients and growth of Corynebacterium amycolatum in one patient. Four patients underwent preoperative computed tomography (CT) of the paranasal sinuses and five patients developed a saddle nose deformity in the long-term follow-up.

Conclusion: All surgical interventions to the nose or cauterization procedures should be performed under sterile conditions, especially in patients with chronic diseases, and such patients should be followed up after the procedure.

Keywords: Septal abscess, epistaxis, electrocauterization.
Correspondence: Mehmet Salih Yağmahan

Department of Otolaryngology, Doç. Dr. Yaşar Eryılmaz Doğubeyazıt State Hospital, Doğubeyazıt, Ağrı, Türkiye

E-mail: msalih_07@hotmail.com

Received: 20.11.2020; Accepted: 17.12.2020
Online available at: www.entupdatesjournal.org 


\section{Introduction}

Nasal septal abscess is a condition characterized by the accumulation of purulent material between the septal cartilage or septal bone and the mucoperichondrium or mucoperiosteum. ${ }^{[1]}$ Septal abscess most commonly occurs following a septal hematoma caused by nasal trauma ${ }^{[2]}$, although surgical interventions, foreign bodies, sinusitis, furunculosis or tooth infections might also be the cause. ${ }^{[1-5]}$ Immune deficiency, diabetes mellitus and sarcoidosis also play a role in the etiology. ${ }^{[6,7]}$

Epistaxis most commonly occurs in the anterior region of the nose known as Kiesselbach's plexus, affecting approximately $60 \%$ of the population. ${ }^{[8]}$ Chemical approaches and electrocauterization are used to control epistaxis in the easily accessible areas of the nose when the nosebleed is not profuse. ${ }^{[9-13]}$ The present study provides a retrospective review of the demographic characteristics of patients who underwent electrocauterization of the nasal mucosa for epistaxis and subsequently developed a nasal septal abscess.

\section{Materials and Methods}

Permission to perform this research was provided by the Frrat University Non-Invasive Research Ethics Committee (No. 2019/10). The study included 11 patients who underwent nasal electrocauterization for epistaxis elsewhere and were subsequently admitted to our clinic with a pre-diagnosis of septal abscess for septal abscess drainage between January 2012 and September 2018. The medical records of the patients, including details such as age, sex, duration of follow-up, symptoms, chronic diseases, microbiological cultures, radiological investigations and complications were retrospectively evaluated.

Treatment involved abscess drainage through a vertical incision to the mucoperichondrium, close to the base of the septum, after which the necrotic tissues in the cavity were aspirated. A penrose drain was placed in the cavity and stabilized with a suture. Anterior nasal packing was performed to prevent accumulation of blood and purulent secretions between the two mucoperichondrial flaps. All patients received intravenous broad-spectrum antibio-therapy during the hospital stay followed by administration of oral anti- biotics after patient discharge for another seven days. In patients with positive growth of microorganisms, the antibio-therapy was prescribed according to the culture and sensitivity results.

Statistical data, including mean values, proportions and standard deviations, were calculated using Microsoft Excel 2010.

\section{Results}

Of the 11 patients included in the study, seven were male $(63.6 \%)$ and four were female $(36.4 \%)$ with a mean age of $66.18 \pm 3.7$ (range 62-76) years. The mean duration of follow-up was $29.09 \pm 17.5$ (range 5-60) months. The mean interval between electrocauterization and abscess formation was $33.5 \pm 11.3$ (range 20-60) days. The mean hospitalization time was 4.9 (4-6) days. All patients had nasal obstruction (100\%) and nasal pain (100\%), whereas five had facial cellulitis (45.4\%), three had a fever $(27.3 \%)$ and two had a headache (18.2\%). Of 11 patients, five patients (45.4\%) had both hypertension and diabetes mellitus, three patients $(27.3 \%)$ had only diabetes mellitus and three patients $(27.3 \%)$ had only hypertension. Of the patients with diabetes mellitus, two had uncontrolled blood glucose levels (fasting blood glucose $>126 \mathrm{mg} / \mathrm{dL}$ and postprandial blood glucose $>200 \mathrm{mg} / \mathrm{dL}$ ) and six had blood glucose levels under control.

The mean duration from nasal electrocauterization to the diagnosis of septal abscess was 33.54 11.33 (range 20$60)$ days. Four patients $(36.4 \%$ ) had preoperative computed tomography (CT) of the paranasal sinuses (Figure 1). Microbiological culture of the purulent material collected during septal abscess drainage revealed no bacterial growth in six patients (54.5\%), growth of Staphylococcus aureus in two patients (18.2\%) and of Corynebacterium amycolatum in one patient $(9 \%)$, whereas microbiological culture samples could not be obtained from two patients (18.2\%). Demographic data and clinical characteristics of the patients are shown in Table 1.

Five patients (45.4\%) developed a saddle nose deformity in the long-term follow-up; no other complications were noted (Figure 2). Of the patients who developed a 


\begin{tabular}{|c|c|c|c|c|c|c|}
\hline No & Age & Gender & Hypertension & DM & Culture & Cauterization Time (days) \\
\hline 1 & 62 & Male & + & + & - & 45 \\
\hline 2 & 64 & Male & + & - & $\varnothing$ & 25 \\
\hline 3 & 63 & Female & + & + & - & 40 \\
\hline 4 & 65 & Female & + & - & - & 33 \\
\hline 5 & 67 & Male & - & + & - & 35 \\
\hline 6 & 76 & Male & + & + & S. aureus & 31 \\
\hline 7 & 67 & Female & - & + & - & 25 \\
\hline 8 & 65 & Male & + & + & S. aureus & 60 \\
\hline 9 & 65 & Male & + & - & $\varnothing$ & 27 \\
\hline 10 & 68 & Female & - & + & - & 28 \\
\hline 11 & 66 & Male & + & + & C. amycolatum & 20 \\
\hline
\end{tabular}

DM: diabetes mellitus $\varnothing$ : microbiological culture samples were not obtained.

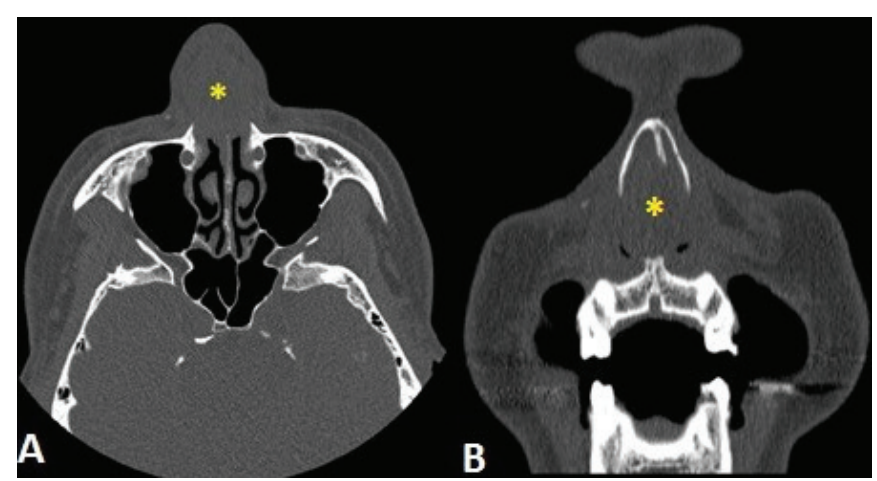

Figure 1. (A) Axial and (B) Coronal CT images of the patient with septal abscess (yellow star indicating septal abscess).

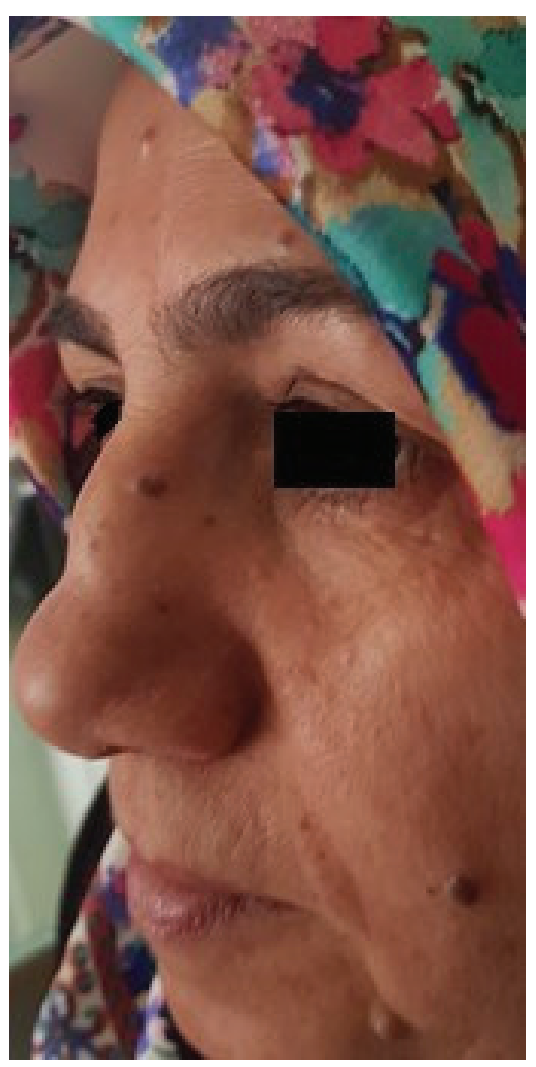

Figure 2. Saddle nose deformity after a septal abscess. 
saddle nose deformity, three had diabetes mellitus and two did not. One patient with diabetes mellitus had uncontrolled blood glucose levels.

\section{Discussion}

Septal abscesses most commonly develop after a nasal injury. ${ }^{[1]}$ The accumulation of a septal hematoma between the septal cartilage and muco-perichondrium after an injury to the nose leads to cartilage ischemia and necrosis, resulting in the development of a septal abscess in the presence of a suitable environment for the growth of microorganisms. ${ }^{[14,15]}$ All the 11 patients included in the present study did not have a history of nasal trauma and had undergone electrocauterization of the nasal septum for epistaxis.

Non-traumatic causes of a septal abscess include nasal furuncle, sinusitis, influenza, uncontrolled diabetes mellitus and immunosuppression. ${ }^{[16-19]}$ In a retrospective review of six patients with nasal septal abscess, Cheng et al. [20] reported the development of septal abscesses due to uncontrolled diabetes mellitus in three patients. Of the 11 patients included in the current study, eight $(72.7 \%)$ were on follow-up for diabetes mellitus, two had uncontrolled blood glucose levels (fasting blood glucose $>126 \mathrm{mg} / \mathrm{dL}$ and postprandial blood glucose $>200 \mathrm{mg} / \mathrm{dL}$ ) and six had blood glucose levels under control. The fact that the majority of our patients $(72.7 \%)$ had diabetes mellitus can be attributed to the greater predisposition of these patients to infection compared to normal individuals.

Kim et al. ${ }^{[2]}$ reported that a septal abscess developed in a patient due to nasal septum electrocauterization. Also, it has been reported in the literature that saddle nose deformity can develop without septal abscess due to electro cauterization. ${ }^{[22]}$ Our study has the highest number of cases in the literature regarding the development of septal abscess due to electrocauterization. Saddle nose deformity developed in five of our patients. Due to electrocauterization for epistaxis, the blood supply of the septal mucoperichondrium and cartilage is impaired. We conclude that septal abscesses may develop as a result of necrosis of the septal cartilage and the inoculation of microorganisms into the electrocauterization area. The defect in the septal cartilage causes saddle nose deformity in the progressive process. Therefore, we think that epistaxis patients undergoing electrocauterization should be followed closely.

In the examination of patients with septal abscess, vital signs, the nasal region and the central nervous system should be evaluated, and nasal endoscopic examination should be performed together with anterior rhinoscopy in nasal examination. Although septal abscess usually involves the anterior cartilaginous part of the nasal septum, there are a few reports of isolated posterior involvement of the nasal septum. ${ }^{[23,24]}$ The most common findings are a swollen, edematous and tender external nose with bilateral purple/dusky looking nasal septal swelling obstructing the airway with or without purulent nasal discharge. ${ }^{[25,26]}$ The most common complaints of the patients in our study were nasal congestion, headache and nasal tenderness. In the anterior rhinoscopy and nasal endoscopy, the abscess location was in the anterior septum in all our patients.

In previous studies, Staphylococcus aureus, Staphylococcus epidermidis, Streptococcus pneumoniae, group A beta-haemolytic Streptococci, Haemophilus influenzae and aerobic bacteria were the most commonly noted microorganisms in the culture tests of patients with septal abscesses. ${ }^{[16-19]}$ In the current study, of the nine patients who had culture tests, Staphylococcus aureus was noted in two patients and Corynebacterium amycolatum was noted in one patient, whereas six patients showed no bacterial growth.

CT imaging can be performed in cases with septal abscess, especially if periorbital cellulitis and intracranial complications are suspected. CT imaging of the paranasal sinuses in patients with septal abscess reveals abscess localization, presence of periorbital cellulitis, intracranial complications and helps differentiate the condition from malignancy. ${ }^{[19]}$ In the current study, four patients underwent CT imaging of the paranasal sinuses, revealing no orbital or intracranial complications.

Management of the septal abscess should include surgical incision and drainage followed by bilateral nasal packing. Also, intravenous antibiotics should be administered against most common pathogens for three to five days, subsequently followed by oral antibiotics based on cul- 
ture and sensitivity results for another seven to 10 days. ${ }^{[15]}$ Surgical drainage with the administration of antibiotherapy was the main treatment modality in the present study. Complications related to nasal septal abscesses, such as sepsis, bacteraemia, meningitis, brain abscess, cavernous sinus thrombosis, maxillary hypoplasia, saddle nose deformity secondary to septal cartilage necrosis and septal perforation may develop. ${ }^{[5,15]}$ In the current study, five patients $(45.4 \%)$ developed a saddle nose deformity, whereas no septal perforation or other intracranial complications were observed. Among the patients with a saddle nose deformity, three $(60 \%)$ had diabetes mellitus and one had uncontrolled blood glucose levels.

\section{Conclusion}

Although trauma is the most common cause of septal abscess, it can also occur because of non-traumatic causes. All surgical interventions or cauterization procedures to the nose must be performed under sterile conditions and local ointments containing antibiotics should be used after the procedure in patients with chronic diseases such as diabetes mellitus, which compromise the immune system and

\section{References}

1. Ambrus PS, Eavey RD, Baker AS, Wilson WR, Kelly JH. Management of nasal septal abscess. Laryngoscope 1981;91:575-82.

2. Adnane C, Adouly T, Taali L, et al. Unusual spontaneous nasal septal abscess. J Case Rep Stud 2015;3:302.

3. Kryger H, Dommerby H. Haematoma and abscess of the nasal septum. Clin Otolaryngol Allied Sci 1987;12:125-9.

4. da Silva M, Helman J, Eliachar I, Joachims HZ. Nasal septal abscess of dental origin. Arch Otolaryngol 1982;108:380-1.

5. Dispenza C, Saraniti C, Dispenza F, Caramanna C, Salzano FA. Management of nasal septal abscess in childhood: our experience. Int J Pediatr Otorhinolaryngol 2004;68:1417-21.

6. Shah SB, Murr AH, Lee KC. Nontraumatic nasal septal abscesses in the immunocompromised: etiology, recognition, treatment, and sequelae. Am J Rhinol 2000;14:39-43.

7. Walker R, Gardner L, Sindwani R. Fungal nasal septal abscess in the immunocompromised patient. Otolaryngol Head Neck Surg 2007;136:506-7.

8. Nemer AK, Motassim AR. Evaluation of conservative measures in the treatment of epistaxis. Khartoum Medical Journal 2008;1:15-7.

9. Bailie N, Hanna B, Watterson J, Gallagher G. A model of airflow in the nasal cavities: Implications for nasal air conditioning and epistaxis. Am J predispose the patient to infection; such patients must be followed up after the procedure.

\section{Acknowledgement: None}

Ethics Committee Approval: The study protocol was approved by the Firat University Non-Invasive Research Ethics Committee (No. 2019/10).

Informed Consent: Written informed consent was not obtained due to the nature of the study.

Author Contributions: Designing the study - A.A., E.K., T.K., İ.K., M.S.Y.; Collecting the data - A.A., M.S.Y.; Analysing the data - A.A., E.K., T.K., İ.K., M.S.Y.; Writing the manuscript - A.A., E.K., T.K., İ.K., M.S.Y., Ş.Y.; Confirming the accuracy of the data and the analyses - S.Y.

Conflict of Interest: The authors have no conflicts of interest to declare.

Financial Disclosure: The authors declare that this study has received no financial support.

Rhinol Allergy 2009;23:244-9

10. Davies K, Batra K, Mehanna R, Keogh I. Pediatric epistaxis: epidemiology, management \& impact on quality of life. Int J Pediatr Otorhinolaryngol 2014;78:1294-7.

11. Damrose JF, Maddalozzo J. Pediatric epistaxis. Laryngoscope 2006;116:387-93.

12. Patel N, Maddalozzo J, Billings KR. An update on management of pediatric epistaxis. Int J Pediatr Otorhinolaryngol 2014;78:1400-4.

13. Elden L, Reinders M, Witmer C. Predictors of bleeding disorders in children with epistaxis: value of preoperative tests and clinical screening. Int $\mathrm{J}$ Pediatr Otorhinolaryngol 2012;76:767-71.

14. Pang KP, Sethi DS. Nasal septal abscess: an unusual complication of acute spheno-ethmoiditis. J Laryngol Otol 2002;116:543-5.

15. Ginsburg CM, Leach JL. Infected nasal septal hematoma. Pediatr Infect Dis J 1995;14:1012-3.

16. Dinesh R, Avatar S, Haron A, Suhana, Azwarizan. Nasal septal abscess with uncontrolled diabetes mellitus: case reports. Med J Malaysia 2011;66:2534.

17. Tien DA, Krakovitz P, Anne S. Nasal septal abscess in association with pediatric acute rhinosinusitis. Int J Pediatr Otorhinolaryngol 2016;91:27-9. 
18. Cain J, Roy S. Nasal septal abscess. Ear Nose Throat J 2011;90:144-7.

19. Huang PH, Chiang YC, Yang TH, Chao PZ, Lee FP. Nasal septal abscess. Otolaryngol Head Neck Surg 2006;135:335-6.

20. Cheng LH, Wu PC, Shih CP, et al. Nasal septal abscess: a 10-year retrospective study. Eur Arch Otorhinolaryngol 2019;276:417-20.

21. Kim T, Kim JS, Heo SJ. Nasal Septal Abscess Developed After Radiofrequency Cauterization for Epistaxis. J Craniofac Surg 2019;30:713-4.

22. In SM, Kim JY. A case of saddle nose deformity caused by electrocautery of nasal septum. [Article in Korean] Korean J Otorhinolaryngol Head Neck Surg 2018;61:532-5.
23. Wallenborn WM, Fitz-Hugh GS. Abscess of the posterior nasal septum. Report of a case. Arch Otolaryngol 1963;77:3-5.

24. George A, Smith WK, Kumar S, Pfleiderer AG. Posterior nasal septal abscess in a healthy adult patient. J Laryngol Otol 2008;122:1386-8.

25. Canty PA, Berkowitz RG. Hematoma and abscess of the nasal septum in children. Arch Otolaryngol Head Neck Surg 1996;122:1373-6.

26. Jalaludin MA. Nasal septal abscess--retrospective analysis of 14 cases from University Hospital, Kuala Lumpur. Singapore Med J 1993;34:435-7.

This is an open access article distributed under the terms of the Creative Commons Attribution-NonCommercial-NoDerivs 3.0 Unported (CC BY- NC-ND3.0) Licence (http://creativecommons.org/licenses/by-nc-nd/3.0/) which permits unrestricted noncommercial use, distribution, and reproduction in any medium, provided the original work is properly cited.

Please cite this article as: Akyigit A., Keleş E., Karlıdağ T., Kaygusuz İ., Yağmahan M. S., Yalçın Ş. Analysis of patients with septal abscess caused by electrocauterization of the nasal septum. ENT Updates 2020;10(3): 418-423 